opinion \& debate

\title{
JEAN O'HARA
}

\section{Learning disabilities services: primary care or mental health trust?}

In the next few months the London Region is expected to publish its strategy for learning disability services in the capital. This will inform the National Service Framework due in the autumn. At the same time, many trusts and health authorities are at various stages of reorganisation and reconfiguration. With the dawning of primary care trusts, single speciality mental health trusts and joint commissioning between health and social services, the debate over where learning disability services are best placed and their interface with mental health services has re-emerged (Barron et al, 2000)

Up until the late 1970s, health services for people with learning disabilities were often based in long-stay learning disability hospitals, with the psychiatrist acting as a medical superintendent. Learning disability was regarded as an illness requiring medical treatment. The shift over the past two decades to community services and a predominantly social model of care has brought about considerable advantage in terms of integration of people with learning disability into mainstream society. Attention moved away from people with learning disabilities being classed as 'unwell' towards greater acceptance of them as individuals with rights and needs.

At the same time, community teams (CTLD) arose out of concerns about the fragmented nature of service. These teams adopted several roles in meeting the health needs of their service user group: direct service delivery and identifying service deficiencies; service development; and inter-agency liaison. This often led to an identified individual programme of care, now an integral part of care management and primarily the responsibility of social services. The NHS and Community Care Act 1990 signalled an urgent need for CTLDs to clarify their specialist health role (Grieg \& Peck, 1998). Such teams are made up of psychiatrists, clinical psychologists, community nurses, speech and language therapists, occupational therapists, behaviour therapists,

physiotherapists and social workers. They provide an extremely diverse range of direct clinical services to a very heterogeneous population (from people with mild learning disabilities to individuals with profound and multiple disabilities), including specialist mental health services, challenging behaviour services, health advocacy and education, communication and social skills training and habilitative programmes.

Recent research (Band, 1998; Department of Health, 1999a) has continued to stress the significant difficulties people with learning disabilities have in accessing mainstream health services, and has identified worrying gaps in service provision from primary care and health screening to secondary and tertiary services. In particular, Signposts for Success (Department of Health, 1998) led CTLDs to embrace issues of advocacy and access to primary care and health services in general. Such provision fits well into a primary care trust configuration. Community teams in their current form are a perpetuation of an institutional model of service where all health needs, generic and specialist, are met by one team, often bypassing general practitioner and primary care services.

People with learning disabilities make up $2 \%$ of the population in the UK. They are at risk of developing severe mental illness, emotional disorders and behavioural disturbances. Rates of psychosis and mood disorders are significantly raised, and studies suggest up to $50 \%$ will have significant mental health problems (Bregman, 1991; Department of Health, 1998).

People with learning disabilities and additional mental health problems and/or severe behavioural problems (dual diagnosis) often have highly complex needs that cannot be met by primary care or mainstream mental health services owing to the lack of experience and understanding of their special needs (Bouras, 1999). Like everyone else in the population, patients who require more specialist input need to be referred to specialist services. These services should be multidisciplinary, local and community-based with access to appropriate in-patient facilities as required (Department of Health, 1993; Holt \& Joyce, 1999). In order to attract the support and resources they need, these small services need to be integrated within mainstream psychiatric services. Mental health services for people without learning disabilities are becoming more multi-disciplinary and community-based. There is clearly a need for people with learning disabilities and mental health problems, who often present with more complex needs, to have a similar range of professionals dedicated to serving them. Unfortunately, there is no mention of their particular needs in the recently published National Service Framework for Mental Health (Department of Health, 1999b). Their needs are often not included in local mental health strategies currently commissioned by primary care groups. The provision and practice of dual diagnosis services is patchy, with some districts not having any specialist community provision at all (Department of Health, 1999a). There is uneven implementation of the Care Programme Approach used in mainstream mental health services, risk assessment procedures and, in some cases, access to approved social workers who have an understanding of special needs. The Royal College of Psychiatrists (1996) recommends the development of specialist mental health teams with expertise in learning disabilities and mental health to provide direct clinical services, ensure coordinated services and effective interagency liaison and to provide training and advice to other agencies. 
These teams need to be tightly focused, with resources specifically targeted at people with dual diagnosis. They cannot be expected to cater for those with borderline intellectual disabilities and mental disorders who often fall between services because their needs cannot be met by standard mental health provision (Hassiotis et al, 1999). Additional resources need to be identified in order to bridge this gap.

Although this makes sound clinical sense, current plans to reorganise health services have aroused overwhelming anxiety in some professional groups allied to medicine, fearful of traditional CTLDs splitting into its physical health care and specialist mental health components. In an attempt to contain this anxiety and perpetuate a familiar model of service delivery, fears of returning to a predominately medical model have reemerged to such an extent that teams have advocated for medical staff to work within a mental health trust. This unnatural splitting, and the unnecessary boundaries that will inevitably emerge, will have a seriously detrimental effect on retention and recruitment of staff into the psychiatry of learning disabilities.

Specialist mental health services for people with dual diagnosis would be well supported in a mental health trust capable of providing a critical mass for recruitment and retention of all mental health staff, clinical governance, continual professional development, research and academic opportunities. Community teams for people with learning disabilities, without its mental health component, would be best supported in a primary care trust. Such an organisation would advocate for the health needs of their local population, while providing a comprehensive range of primary care services and secondary health care referrals, with the general practitioner as the gatekeeper of health care. The current wave of health service reorganisation provides an exciting opportunity for learning disability services to seize the issues and to go forward, while learning the lessons of the past.

pinion

\& debate

\section{References}

BAND, R. (1998) The NHS - Health for All? London: Mencap National Centre.

BARRON, P., HASSIOTIS, A. \& O'HARA, J. (2000) Learning disability mental health services: what is the future? British Medical Journal, in press.

BOURAS, N. (1999) Mental health and learning disabilities: planning and service developments. Tizard Learning Disability Review, 4, 3-5.

BREGMAN, J. D. (1991) Current developments in the understanding of mental retardation. Part II.

Psychopathology. Journal of American Academy of Child and Adolescent Psychiatry, 30, 861-872.

DEPARTMENT OF HEALTH (1993) Challenging Behaviours and/or Mental Health Needs of People with Learning Disabilities (The Mansell Report). London: HMSO.

— (1998) Signposts for Success in Commissioning and Providing Health Services for People with Learning Disabilities. London: The Stationery Office.

- (1999a) Facing the Facts. Services for People with Learning Disabilities. A Policy Impact Study of Social Care and Health Services. London: The Stationery Office.

_ (1999b) Modern Standards and Service Models: Mental Health National Service Framework. London: The Stationery Office.

GRIEG, R. \& PECK, E. (1998) Is there a future for the community learning disabilities team? Tizard Learning Disability Review, 3, 35-41.

HASSIOTIS, A., UKOUMUNNE, 0 TYRER, P et al (1999) Prevalence and characteristics of patients with severe mental illness and borderline intellectual functioning. British Journa of Psychiatry, 175, 135-140.

HOLT, G. \& JOYCE,T. (1999) Mental health and challenging behaviour services. Tizard Learning Disability Review, 4, 36-42.

ROYAL COLLEGE OF PSYCHIATRISTS (1996) Meeting the Mental Health Needs of Adults with Mild Learning Disabilities. Council Report CR56. London: Royal College of Psychiatrists.

Jean O'Hara Consultant Psychiatrist in Learning Disabilities, The Royal London Hospital, 130a Sewardstone Road, London E2 9HN 